\title{
Telemedicine and Health Care in Indian Context
}

\section{S. Christian D. ${ }^{1}$, A. Giri P. ${ }^{2 *}$}

DOI: https://doi.org/10.17511/ijphr.2018.i3.04

1 Donald S. Christian, Assistant Professor, Department of Community Medicine, GCS Medical College, Ahmedabad, Gujarat, India.

2* Purushottam A. Giri, Professor \& Head, Department of Community Medicine, IIMSR Medical College, Jalna, Maharashtra, India.

With the advancements in information technology and audio-visual aids, one should not wonder if medical consultations are provided through it. India is unique country with respect to variations in geographical structure starting from Himaliyan hills to the deserts of Rajasthan and Gujarat and then to the seashores of southern India. It could be emphasized that India would be benefitted the most taking large number of remote, scatter and underserved areas of the country. The term "Health Telematics" means "A composite term for health related activities, services and systems, carried out over a distance by means of information and communication technologies, for the purpose of global health promotion, disease control and health care as well as education, management and research in health." On the other hands, the term e-health means combined use in health sector of electronic communication and Information technology, for clinical, education and administrative purposes both at the local site and at the distance [1].

Keywords: Geographical structure, Health Telematics, Education, Electronic communication and Information technology, Local site

Corresponding Author

Purushottam A. Giri, Professor \& Head, Department of Community Medicine, IIMSR Medical College, Jalna, Maharashtra, India.

Email: drpgiri14@gmail.com
How to Cite this Article

Christian DS, Giri PA. Telemedicine and Health Care in Indian Context. Public Health Rev Int J Public Health Res. 2018;5(3):123-124.

Available From

https://publichealth.medresearch.in/index.php/ijphr/ article/view/93
To Browse

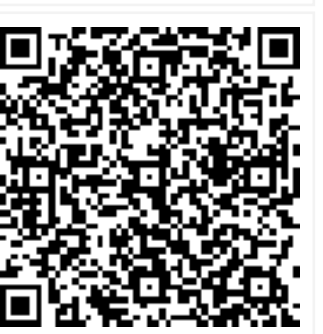

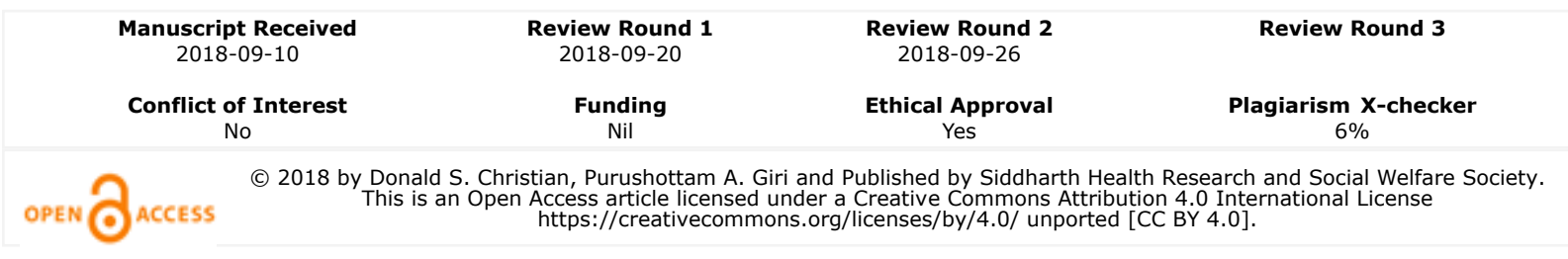




\section{Dear Sir,}

With the advancements in information technology and audio-visual aids, one should not wonder if medical consultations are provided through it. India is unique country with respect to variations in geographical structure starting from Himaliyan hills to the deserts of Rajasthan and Gujarat and then to the seashores of southern India.

It could be emphasized that India would be benefitted the most taking large number of remote, scatter and underserved areas of the country. The term "Health Telematics" means "A composite term for health related activities, services and systems, carried out over a distance by means of information and communication technologies, for the purpose of global health promotion, disease control and health care as well as education, management and research in health."

On the other hands, the term e-health means combined use in health sector of electronic communication and Information technology, for clinical, education and administrative purposes both at the local site and at the distance [1].

The term "telemedicine" was first coined in the late 20th century by the European Union which mainly focuses the aspects of service delivery through the use of appropriate information and communication technologies. The definition of telemedicine is quite comprehensive and includes all the possible aspects of its usage.

The term is defined as follows: The delivery of health care services, where distance is a critical factor, by health care professionals using information and communication technologies for the exchange of valid information for the diagnosis, treatment and prevention of diseases and injuries, research and evaluation, and for continuing education for health care providers, all in the interest for advancing the health of individual and their communities [2].

There are mainly two types of Telemedicine: Real time telemedicine (synchronous) and Store and forward telemedicine (asynchronous). The former transfers live data like ultrasound of Doppler images. The former is mainly used during emergency medical situations.

The later type is mainly used for running out-patient departments where the data is captured and stored for remote centers.
As India had got large area and population size, the store and forward medicine has potential to be utilized for the underserved areas. There are issues like urban-rural divide, inaccessible hilly regions/islands and many tribal areas. There are certain strengths of introducing the system in India [3].

They include the followings:

01. It already has its own satellite communications in place.

02. There is large mass of trained human resource available.

03. A number of successful pilot projects in place.

The WHO recommends that ICT is also quite applicable to developing countries like us [4]. Nowadays, there are computers in many, if not all peripheral centers, such as PHCs. The question is to allow them to connect and to use them.Main challenge is their optimum utilization and avoiding diverting resources from basic needs. There needs to be a balance between procurement of such devices and their usage for the benefit of the health care.

There have been some achievements with respect to practice of telemedicine in the country so far. For examples, about 78 remote hospitals have been connected to 22 specialist hospitals of the country. Hospitals in Leh and Kargil are now connected to the AIIMS and Apollo Hospitals, New Delhi [5].

The remotest islands of Lakshdweep were connected to the Amritha Institute of Kochi. This has also benefited the hard to reach areas of North-East states where few of the hospitals are connected to the Asia Heart Foundation, Kolkata.

There are certain benefits through telemedicine in healthcare. First of all, it makes special consultations possible from the remotest of the site. It just requires a viable internet connection and the telemedicine audio-visual equipment.

Thus it reduces the cost and the hazards due to possible long distance travel. Further, apart from service provision, it can also be used for education purposes as well. For example, Tele-CMEs are quite prevalent in the names of webinars. A competent system will help many emergency situations as well. Sometimes the system helps for follow-up care where the physical presence might not be so much desirable. 
The telemedicine has also improved a lot on the remote ICCU monitoring.The potential beneficiaries are those involved in the rural health care, corporate health centers (that can reduce cost of care), remote location health industries etc.

It has drastically reduced the professional isolation of the peripheral health care providers and has led to lesser complications to the patients [6]. It has minimized the need for the patients for attending hospitals. It must also be noted that the electronically generated data can improve quality of care and safety of remedies and can Increase the cost-effectiveness.

There are certain barriers to the use on the other hand. First and foremost is the lack of technical knowledge among the care givers. This is especially important for older staff. Sometimes there isn't an optimum support from the organization. Sometimes the care providers themselves are not keen to change for using the technology. It must also be noted that telemedicine cannot work as "rocket science".

It requires lots of motivation, trainings, support, funds etc. it also demands proper planning, computer literacy and strategies to make it costeffective activity. Government commitment is most important as it requires long term plans, sustainable finances and cooperation from health authorities. Government support is also needed for providing legislative framework for smooth functioning.

Lack of awareness among the physicians, low levels of rapport among them, improper schedulings of the duties, poor technical support and connectivity issues are some of the major drawbacks of the practice of telemedicine in India so far.

\section{Conclusion}

Telemedicine and e-health are not made only for developed countriesas one would have thought. India is a country with tremendous potential for practicing telemedicine. Its implications in primary health care are well established.For our country, what is desired is the optimum use of e-health to get maximum benefits keeping scarce resources for basic services.

\section{Reference}

01. World Health Organization (WHO). Department of Essential Health Technologies. www. who.

int/eht [Crossref]
02. European Regional Office. WHO. Available at: [Article] [Crossref]

03. World Health Organization. Health and sustainable development-Telehealth.

Available at: [Article] [Crossref]

04. World Health Organization (WHO). Role of Telemedicine in health care.

Available at: [Article] [Crossref]

05. Kishore J. National Health Programs of India, Telemedicine. Seventh edition. 2007;486-87. [Crossref]

06. Patel V. A presentation on Telemedicine, idiagnosis technologies, 2010, Ahemdabad. [Crossref] 